\title{
Title:
}

\section{Fretting Corrosion Behavior of Nitinol Spinal Rods in Conjunction with Titanium Pedicle Screws}

\author{
Elena Lukina, Mikhail Kollerov 1 , Jay Meswania2, Alla Khon 1 , Pavel \\ $\operatorname{Panin}_{3}$, Gordon W. Blunn 2
}

1 -MAI (National Research University), Moscow, Russia (125993, Volokolamskoeshosse.,4)

2 - University College London, London, UK (Brockley Hill, Stanmore, HA7 4LP)

3 - VIAM, Moscow, Russia (105005, 17 Radio street)

\section{Corresponding author:}

Elena Lukina

e-mail: elenaalukina@ rambler.ru lukinaea@mati.ru

Tel. +(916) 2266225

Permanent postal address for correspondence:

KT70DY

4 GREENWOOD ROAD

THAMES DITTON

SURREY

UK

Key words: Nitinol; fretting; corrosion; spine; retrieval; pedicle screws 
Key words: Nitinol; fretting; corrosion; spine; retrieval; pedicle screws

INTRODUCTION: Nitinol (approximately 50 at. \% Ni, 50 at. \% Ti), an alloy with shape memory effect and super-elasticity, has been successfully used for decades as an implantable material for medical devices such as stents, orthodontic wires and spinal implants [1-2]. The presence of $\mathrm{Ni}$, a cytotoxic ion, has led to extensive research on the biocompatibility of this material. Generally it is considered that Nitinol has good biocompatibility, due to the formation of a passive titanium-oxide layer $\left(\mathrm{TiO}_{2}\right)$ similar to that found on $\mathrm{Ti}$ and its alloys [3-4]. In-vitro studies have shown that in simulated physiological solutions Nitinol is less resistant to chemical breakdown than Ti6Al4V, but more resistant than 316L stainless steel [5]. Moreover, after proper preparation of the surface, which might include electropolishing or chemical etching, Nitinol demonstrates even higher corrosion resistance [3]. The rate of $\mathrm{Ni}$ ions release from Nitinol is considered to be comparable with that from medical stainless steel and much less of a burden than that associated with the average dietary intake [6-8].

Recently, application of Nitinol in implantable devices where components of this alloy may contact with other materials is being considered. One of the most promising uses of Nitinol are rods in spine pedicle screw constructs used for the surgical treatment of scoliosis and degenerative spine diseases, where the rods are attached to the vertebra bodies with pedicle screws (Figure 1). Use of super-elastic Nitinol in such a device makes dynamic stabilization possible by retaining functional mobility of the operated spine, which is aimed to prevent long-term complications such as adjacent segment degeneration [9-11]. Pedicle screws made of titanium alloys are normally considered the best choice for constructs with Nitinol rods since the surfaces of both metals are covered with similar $\mathrm{TiO}_{2}$ protective oxide layers and in-vitro studies have demonstrated that Nitinol has a high resistance to galvanic corrosion when coupled with titanium alloys [1213]. In-vitro fatigue tests of pedicle screw constructs with Nitinol rods and short-term clinical outcomes also demonstrated good results [11, 14-15].

However, one of the recent in-vitro studies showed corrosion between previously scratched Nitinol rods locked in Ti6Al4V pedicle screw in $0.9 \% \mathrm{NaCl}$ solution with an extensive built-up of titanium oxide as a corrosion byproduct. However, this corrosion damage was not seen in every instance and the reason for its sporadic occurrence is unclear [16].

The first results of our previous work on the analysis of Nitinol rods retrieved from patients after short-term implantation did not show any evidence of corrosion and $\mathrm{Ni}$ ions in the blood were not elevated compared with preoperative levels [15]. However, in two rods recently retrieved after 12 months corrosion was seen in the areas where the rods were locked into titanium pedicle screws. It is acknowledged now that the restoration of the scratched protective oxide layer on Nitinol surface is rather slow [4, 17]. It was therefore hypothesized that the damage to this layer on Nitinol during fretting process might deteriorate its 
corrosion resistance and accelerate electrochemical corrosion between Nitinol rods and titanium pedicle screws. It might be suggested that more intensive fretting damage would cause more severe corrosion of Nitinol. Since the development of such corrosion might result to nickel leaching and premature failure of Nitinol components in implantable constructs where this material contacts element made of titanium alloys, detailed investigation of these processes is necessary.

The aim of this study was to investigate the fretting corrosion behavior of Nitinol spinal rods under in-vitro condition in conjunction with titanium (Ti6Al4V) pedicle screws of different designs, which provided different mobility of the rods inside them. Also, the aim was to examine the corrosion patterns observed after these in-vitro tests and compare them to those observed on the two retrieved Nitinol rods described above.

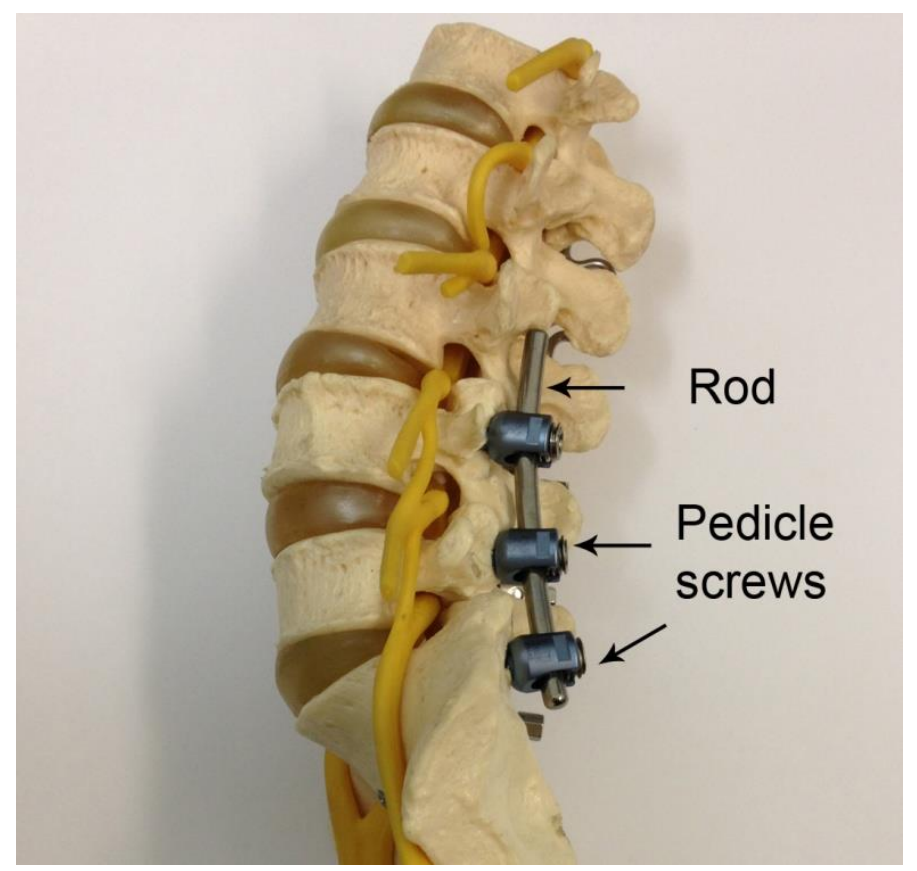

Figure 1. Pedicle screw device

\section{Materials and Methods}

\subsection{Analysis of retrieved Nitinol rods}

138 operations with pedicle screw instrumentation were carried out in the Central Institute of Traumatology and Orthopedics (CITO), Moscow, Russia under the Institute ethical approval. Patients (mean age 53 years old, range 40-82) were operated for degenerative disease (65 patients) and degenerative scoliosis (73 patients) and all had at least 2 years follow-up. Instrumentation was at the L1-L5 spine levels. In these operations posterior instrumentation included two super-elastic Nitinol rods and polyaxial pedicle screws made of titanium alloy Ti6Al4V. The chemical composition and structure of implanted Nitinol rods corresponded to ASTM F2063-12. The surface of the rods was electropolished. In order to achieve dynamic stabilization, interbody fusion was not performed for these patients. 4 of 138 patients underwent revision 
surgery because of resorption of bone around the screws resulting in instability after 12-13 months postimplantation. Nitinol rods in each case were explanted (eight rods in total). The retrieved implants were thoroughly rinsed under running water followed by rinsing in $80 \%$ aqueous ethanol solution and subsequent ultrasonic cleaning. After that implants were decontaminated by autoclaving.

The cleaned rods were examined with unaided eye and using a stereomicroscope (Stemi $2000 \mathrm{C}$, Carl Zeiss, Jena, Germany) at magnifications up to $\times 90$. Photographic recording of the rods was carried out. Two Nitinol rods retrieved from one of these patients had corrosion marks in an area of their contact with titanium screws. These areas were analyzed using scanning electron microscopy (SEM) and energy dispersive X-ray analysis (EDAX) on FEI Quanta 200 microscope (FEI, USA) at an accelerating voltage of $20 \mathrm{kV}$. Focused Ion Beam (FIB) slicing with Ga beam was used to study the underlying boundary between the corrosion deposits and the substrate Nitinol rod.

The concentration of $\mathrm{Ni}$ ions in the whole blood of this patient and in the tissues collected around the rod and screw junction were also measured. The amount of Ni in the blood was compared to that measured in these patients before the surgery, while $\mathrm{Ni}$ content in the tissues was compared to the values in the control group of patients $(\mathrm{n}=8)$ without any implants.

To limit possible contamination with $\mathrm{Ni}$, venipuncture was performed with cannula. Venous blood specimens were collected into the green-cap Vacuette (sodium heparin containing) collecting tubes (Greiner Bio-One International AG, 4550 Kremsmünster, Austria) and diluted 1:30 with an acidified diluents ((v/v) of $1 \%$ 1-Butanol, $0.1 \%$ Triton $\mathrm{X}-100$ and $0.07 \% \mathrm{HNO}_{3}$ in distilled deionized water (DDIW)). The amount of $\mathrm{Ni}$ was measured using inductively-coupled mass spectrometry method (ICP-MS) using Nexion 300D ICP-MS spectrometer (PerkinElmer Inc., Shelton, CT 06484, USA). ClinChek Control for trace elements standard (Recipe, Munich, Germany) was employed to calibrate the ICP-MS results.

Soft tissues were digested with $\mathrm{HNO}_{3}$ in the Berghof SW-4 DAP-40 microwave system (Berghof Products + Instruments GmbH, 72800 Eningen, Germany), diluted 1:150 with DDIW and run into the ICPMS system within 2-3 hours.

\subsection{In-vitro fretting corrosion tests}

Since there is no standard for the evaluation of fretting corrosion resistance of spinal constructs, ASTM F1875 for the evaluation of fretting corrosion of modular implant interfaces was used as a guideline in our tests. Nitinol rods $(\varnothing 5.5 \mathrm{~mm}, 1=76 \mathrm{~mm})$ were locked in set screws $(\mathrm{SS})$ or taper locked (TL) pedicle screws made of titanium alloy (Ti6Al4V) without any surface modification (Figure 2a) and fretting corrosion tests were carried out using 3-point bending (Figure 2b).

In the SS pedicle screw system, the rod is locked by fixing the screw nut with a set amount of torque. In the TL system, the rod is locked by press-fitting it in the inner collet. It was hypothesized that 
a larger contact area between rod and screw in TL system (approximately $55 \mathrm{~mm}^{2}$ for TL and $26 \mathrm{~mm}^{2}$ for SS systems) would result in less mobility of the rod during cyclic loading, decreasing the damage to the passive layer thus reducing fretting corrosion. Pedicle screws from the retrieved spine construct where the corrosion damage was observed on Nitinol rods and SS screws used in the in-vitro tests were of the same design and from the same manufacturer.

Behavior of titanium (Ti6Al4V) and $\mathrm{CoCr}$ rods attached to the same screw designs was also studied. All combinations of tested samples are given in Table 1. An $n=3$ number of samples was used for each screw and rod combination.

\section{Set screw}

(SS)

Open

?
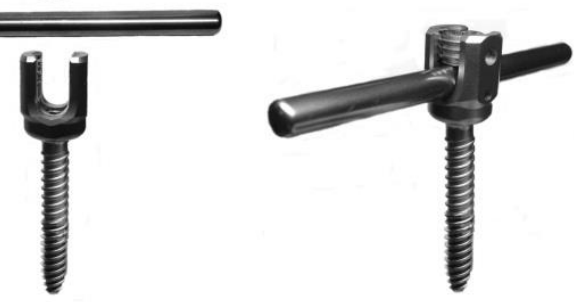

Taper Lock screw

(TL)

Open

Closed
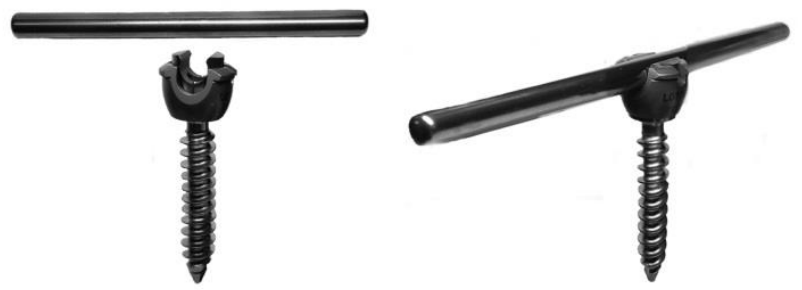

a)

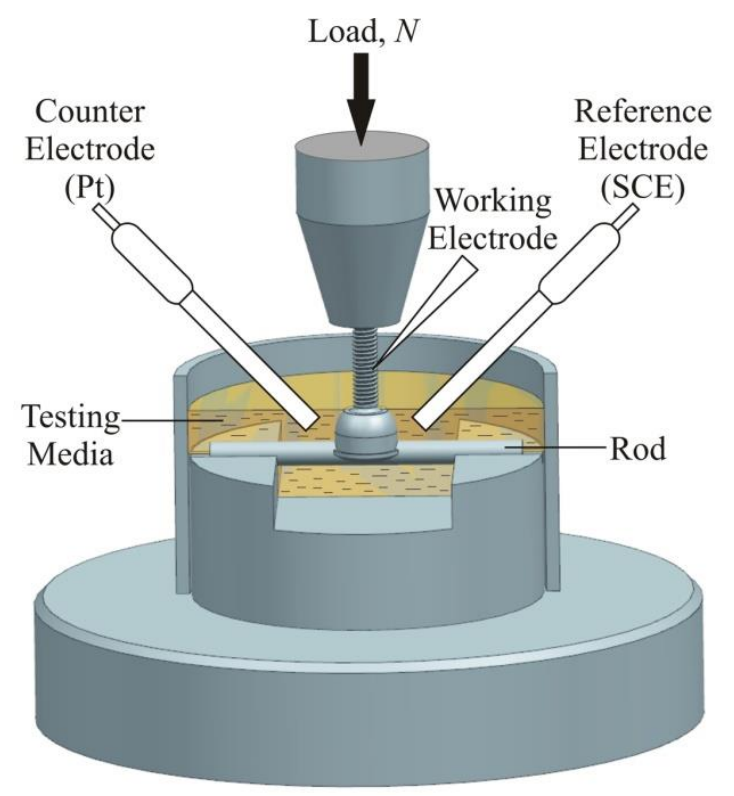

b)

Figure 2. a) Photo of set screw (SS) and taper locked (TL) pedicle screw systems. In SS system the rod is locked by fixing the screw nut with the preset amount of torque. In TL system rod is locked by pressfitting it into the inner collet; b) Set up for fretting corrosion test 
Table 1. Sample description

\begin{tabular}{|c|c|c|}
\hline \multicolumn{3}{|c|}{ Short-term tests } \\
\hline Test No. & Rod material & Pedicle screw type \\
\hline 1.1 & Nitinol & \multirow{3}{*}{ Set screw "SS" } \\
\hline 1.2 & Ti6Al4V & \\
\hline 1.3 & $\mathrm{CoCr}$ & \\
\hline 1.4 & Nitinol & \multirow{3}{*}{ Taper locked "TL" } \\
\hline 1.5 & Ti6Al4V & \\
\hline 1.6 & $\mathrm{CoCr}$ & \\
\hline \multicolumn{3}{|c|}{ Long-term tests } \\
\hline 2.1 & \multirow{2}{*}{ Nitinol } & Set screw "SS" \\
\hline 2.2 & & Taper locked "TL" \\
\hline
\end{tabular}

\section{Materials}

\section{Rods}

Nitinol rods $(55.8 \mathrm{wt} \% \mathrm{Ni}), 5.5 \mathrm{~mm}$ in diameter, used in the tests were hot worked, center-less ground to final dimensions and subjected to barrel grinding and electro-polishing. The surface roughness of Nitinol rods was Ra $0.04 \pm 0.01 \mu \mathrm{m}$. All rods were heat treated and were in an austenitic state at the test temperature. Their temperature of shape recovery $\left(\mathrm{A}_{\mathrm{f}}\right)$ was measured by bend and free recovering method (ASTMF2082). Phase composition of rods was represented by austenitic B2 phase, nanosize Ni-rich particles of $\mathrm{Ni}_{4} \mathrm{Ti}_{3}$ and $\mathrm{Ni}_{3} \mathrm{Ti}_{2}$, and $\mathrm{Ti}$-rich $\mathrm{Ti}_{4} \mathrm{Ni}_{2} \mathrm{O}_{x}$ particles. Since the large size and volume fraction of $\mathrm{Ti}_{4} \mathrm{Ni}_{2} \mathrm{O}_{\mathrm{x}}$ particles are reported to reduce corrosion resistance of Nitinol [18], these particles were characterized by taking 10 micrographs of electropolished Nitinol sample without subsequent etching by scanning electron microscopy. The micrographs were processed using ImagePro3 (Nexis, Russia) software and average and maximal size and volume fraction of these particles were evaluated.

For comparison, fretting corrosion resistance was also measured for titanium (Ti-5.8 wt.\%Al-4.1 wt.\%V) and cobalt chromium (Co-13wt.\% Cr-7 wt.\% Mo) commercial rods (K2M, VA, USA). These rods had sand-blasted surface finish. The surface roughness of titanium rods was Ra $0.85 \pm 0.15 \mu \mathrm{m}$ and that of cobalt chromium rods was Ra $0.80 \pm 0.2 \mu \mathrm{m}$.

The baseline corrosion resistance of Nitinol, Ti6Al4V and CoCr rods was determined by performing potentiodynamic polarization of 3 samples in accordance with ASTM F2129. Before the tests, these samples were ultrasonically degreased, rinsed in distilled water and dried. Testing was performed in a phosphate buffered saline (PBS) solution (Sigma Aldrich, USA). The composition of this solution is given in Table 2. The reference electrode was a saturated calomel electrode (SCE), the counter electrode was platinum and the rate of polarization was $0.167 \mathrm{mV} / \mathrm{s}$. The samples were immersed into the solution and the rest potential $\left(\mathrm{E}_{\mathrm{r}}\right)$ was monitored for $1 \mathrm{~h}$. The surface area of the rods in contact with the solution was $4.5 \mathrm{~cm}^{2}$. After that, samples were polarized up to $+1000 \mathrm{mV}$ versus SCE and outcome recorded. 
Table 2

Chemical composition of Phosphate buffered saline solution

\begin{tabular}{|l|l|}
\hline Component & Concentration $(\mathrm{g} / \mathrm{L})$ \\
\hline $\mathrm{NaCl}$ & 8.0 \\
\hline $\mathrm{KCl}$ & 0.2 \\
\hline $\mathrm{Na}_{2} \mathrm{H}_{2} \mathrm{PO}_{4}$ & 1.15 \\
\hline $\mathrm{KH}_{2} \mathrm{PO}_{4}$ & 0.2 \\
\hline
\end{tabular}

\section{Pedicle screws}

Both SS and TL pedicle screws were made from titanium alloy Ti6Al4V without any surface treatment (anodization layers sometimes used for marking purposes). Both screw designs have been used clinically.

\section{Methods}

\section{Short-term tests}

Prior to testing, all the rods and pedicle screws were ultrasonically cleaned, rinsed in distilled water, dried and assembled using the instruments designed for each screw type. After assembly, the rod was immersed in the electrolyte solution in the test chamber and the potential was monitored for 1 hour. The electrolyte used was $10 \%$ solution of calf serum in phosphate buffer saline (Sigma Aldrich, USA). The reference electrode was a saturated calomel electrode (SCE), the counter electrode was platinum. A sinusoidal cyclic load between $100 \mathrm{~N}-650 \mathrm{~N}$ at $1 \mathrm{~Hz}$ was then applied (Figure 2b) using a hydraulic loading machine (RDP Howden Ltd., UK) and potentiostatic measurements of the fretting current between the implant and the counter-electrode was carried out at a potential of $200 \mathrm{mV}$ by using Metrohm Autolab PGSTAT 101 multi-channel modular potentiostat/galvanostat. There was no electrical insulation between the rod and the screw and the potential was applied to the whole rod/pedicle screw system. Spinal rods are designed to withstand 6.5-7 $\mathrm{Nm}$ of bending moment [19]. An accelerated test was used in the short term testing where a maximal load of $650 \mathrm{~N}$ resulting in a bending moment of $12.4 \mathrm{Nm}$ was applied.

Before loading the current was monitored for 400 seconds. During this period the current reached a stable value. After the application of cyclic load, fretting corrosion current was measured for up to 3600 cycles. Figure 3 presents a typical fretting corrosion curve. A sharp increase of the current can be seen immediately after the loading; after which the current decreases reaching a stable value (Figure 3). Analysis of all fretting corrosion current curves revealed that the samples studied in this work reached their stable value (10\% accuracy) after 2000 loading cycles. For this reason, an average peak-to-peak values of fretting corrosion current between 2000 and 2010 cycles was used for further analysis (Table 1). Statistical analysis was carried using a t-test. 
Rods and pedicle screws were disassembled after the tests, cleaned and dried. The rod surface was then analyzed using SEM and EDAX analysis.

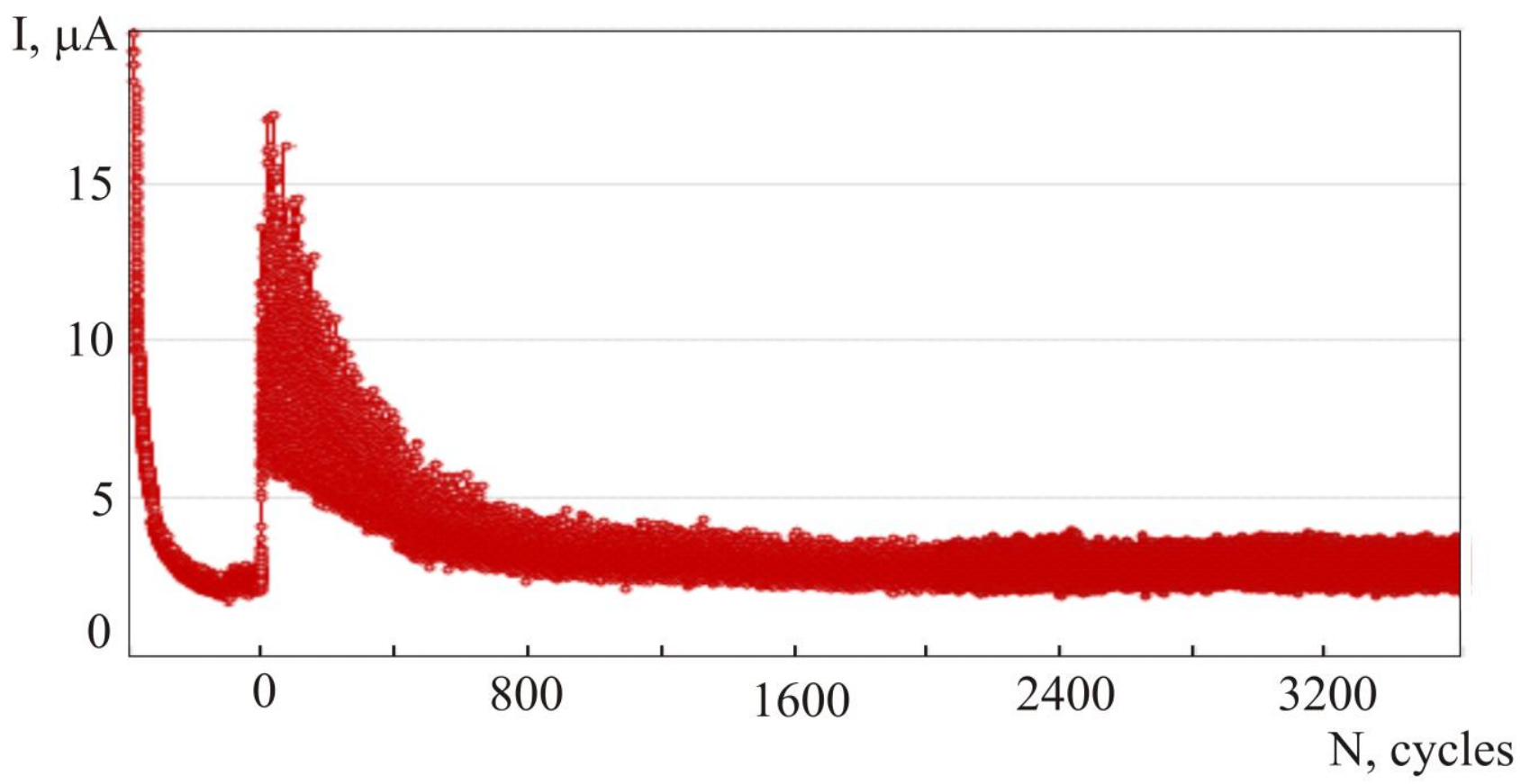

Figure 3. Potentiostatic tests - Typical fretting corrosion current response to sinusoidal 3-point bending loading of rods locked in pedicle screws

\section{Long-term tests}

Long-term tests were performed using cyclic loading on the Nitinol rods locked in SS and TL pedicle screws (Table 1) at $3 \mathrm{~Hz}$ for 2 million cycles. Peak load applied was $350 \mathrm{~N}$, which provided a bending moment of $6.6 \mathrm{Nm}$. The rods are expected to withstand this load without fatigue failure. During the final 3600 cycles, the maximal peak load was increased to $650 \mathrm{~N}$ and peak-to-peak values of fretting corrosion current were measured as described before for the short-term tests. The surface of rods was analyzed using SEM and EDAX analysis. The test fluid was collected and the content of $\mathrm{Ni}, \mathrm{Ti}, \mathrm{Al}$ and $\mathrm{V}$ was analyzed using Nexion 3D ICP-MS (PerkinElmer Inc., Shelton, CT 06484, USA). ClinChek Control for trace elements standards (Recipe, Munich, Germany) were employed to calibrate the ICP-MS results.

\section{Results}

\subsection{Analysis of retrieved Nitinol rods with Ti6Al4V pedicle screws}

In total 8 rods explanted from 4 patients were examined. In all cases rods were locked in titanium pedicle screws of the same SS design (Figure 2a). The same screw design was later used in our in-vitro fretting corrosion tests. 6 rods retrieved from 3 patients had minor scratches but no other corrosion marks in the form of pitting or other patterns were observed. The remaining two rods explanted from the fourth patient had atypical discolored regions adjacent to the pedicle screws (Figure 4a). These two rods were explanted at the revision operation, 12 months after the initial surgery due to pedicle screw loosening. The 
shape and location of the observed discolored regions matched the design and location of pedicle screw heads (Figure 4a) indicating the area was within the clamped section of the screw. It can be seen in Figure 4a that the discoloration was variable between different screw sites along the length of rod being more pronounced under some screw heads, while almost no marks can be noted under the others.

SEM analysis of the discolored region showed erosion craters adjacent to the build-up of corrosion deposits (Figure $4 \mathrm{~b}$ and $\mathrm{c}$ ). No pitting was found outside the discolored regions. The varying brightness of the undamaged surface and corrosion deposit on the SEM image in backscattered electrons mode indicates their different chemical composition (Figure 4c). EDAX analysis revealed normal titanium to nickel distribution (43-44 at.\% of $\mathrm{Ti}, 47-48$ at.\% $\mathrm{Ni}$ and up to 10 at.\% O; average values based on the analysis of 5 locations) in the area without corrosion damage (Figure 4c and 5). On the other hand, the corrosion deposit contained 20-22 at.\% Ti, 48-50 at.\% $\mathrm{O}$ and only up to 1 at.\% of $\mathrm{Ni}$ (average values based on the analysis of 5 locations), which is consistent with titanium oxide $\mathrm{TiO}_{2}$ (Figure $4 \mathrm{c}$ and 5). Other elements observed in the deposit were $\mathrm{C}, \mathrm{Ca}$ and $\mathrm{P}$ which might be the result of contamination.

Focused Ion Beam slicing was used to study the underlying boundary between the oxide deposit and the substrate Nitinol rod. A slot $15 \times 40 \mu \mathrm{m}$ in size and $40 \mu \mathrm{m}$ in depth was cut on the surface of Nitinol rod in the area of the corrosion deposit. The cross-section of the boundary oxide deposit/substrate was examined using SEM in secondary and backscattered electrons (Figure $4 \mathrm{~d}$ and e respectively). This showed that the oxide deposit was located inside the eroded areas. Since Nitinol contains approximately 50 at. \% Ti and 50 at. $\% \% \mathrm{Ni}$, it is suggested that erosions are the result of electrochemical corrosion with $\mathrm{Ti}$ ions forming oxide as a corrosion product and releasing $\mathrm{Ni}$ ions into the surrounding media. These $\mathrm{Ni}$ ions can accumulate in the surrounding tissues and also may be transferred into the blood. 

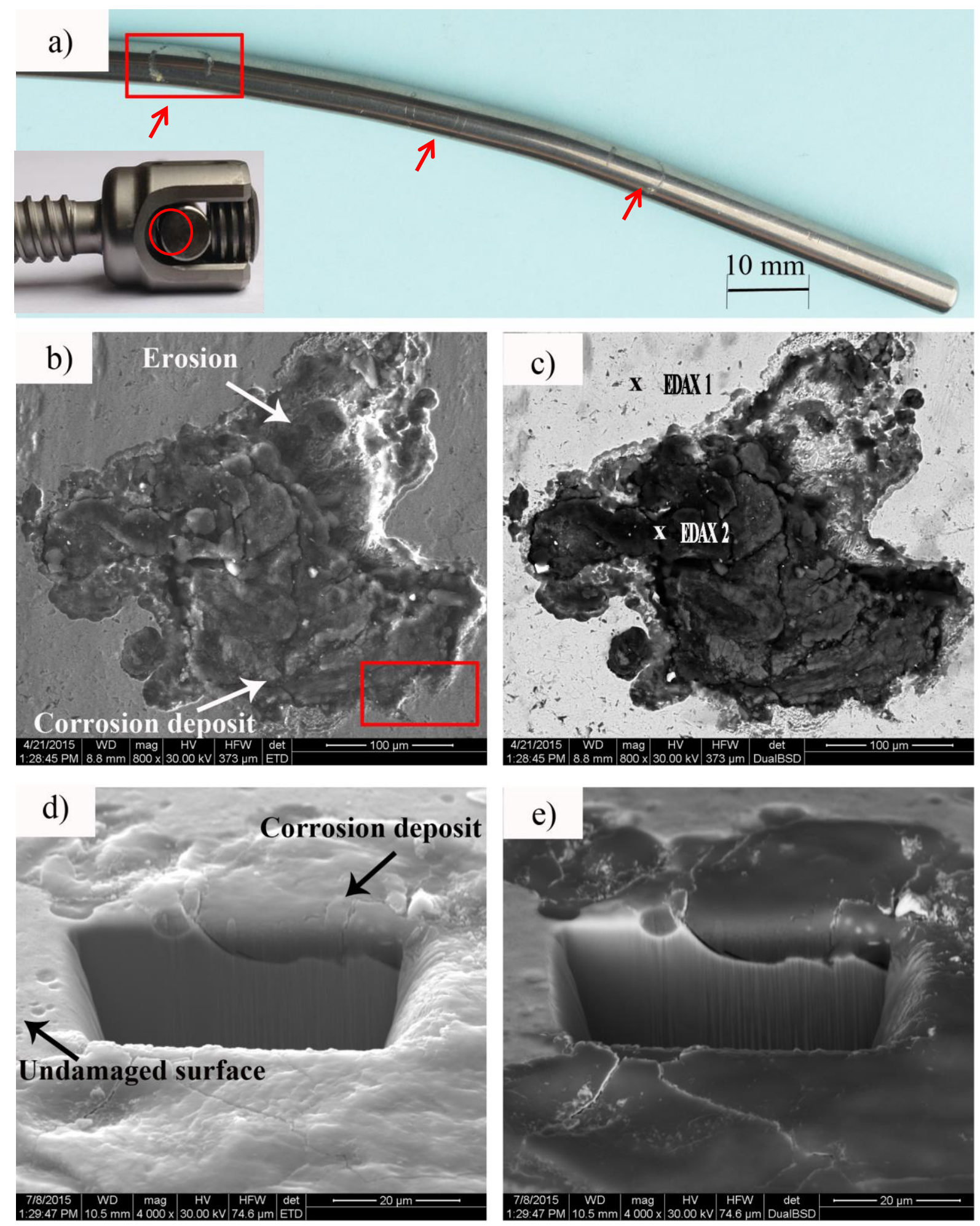

Figure. 4. (a) A photo of explanted Nitinol spinal rod with corrosion damage observed under the head of titanium pedicle screw (SS type) after 12 months of implantation; (b) and (c) SEM image of the corroded area (marked in red in (a)) in secondary electrons (b) and backscattered electrons (c) modes; (d) and (e) cross-section of corrosion deposit (titanium oxide) / substrate Nitinol rod boundary in secondary and backscattered electrons mode respectively (marked in red in (b)) 


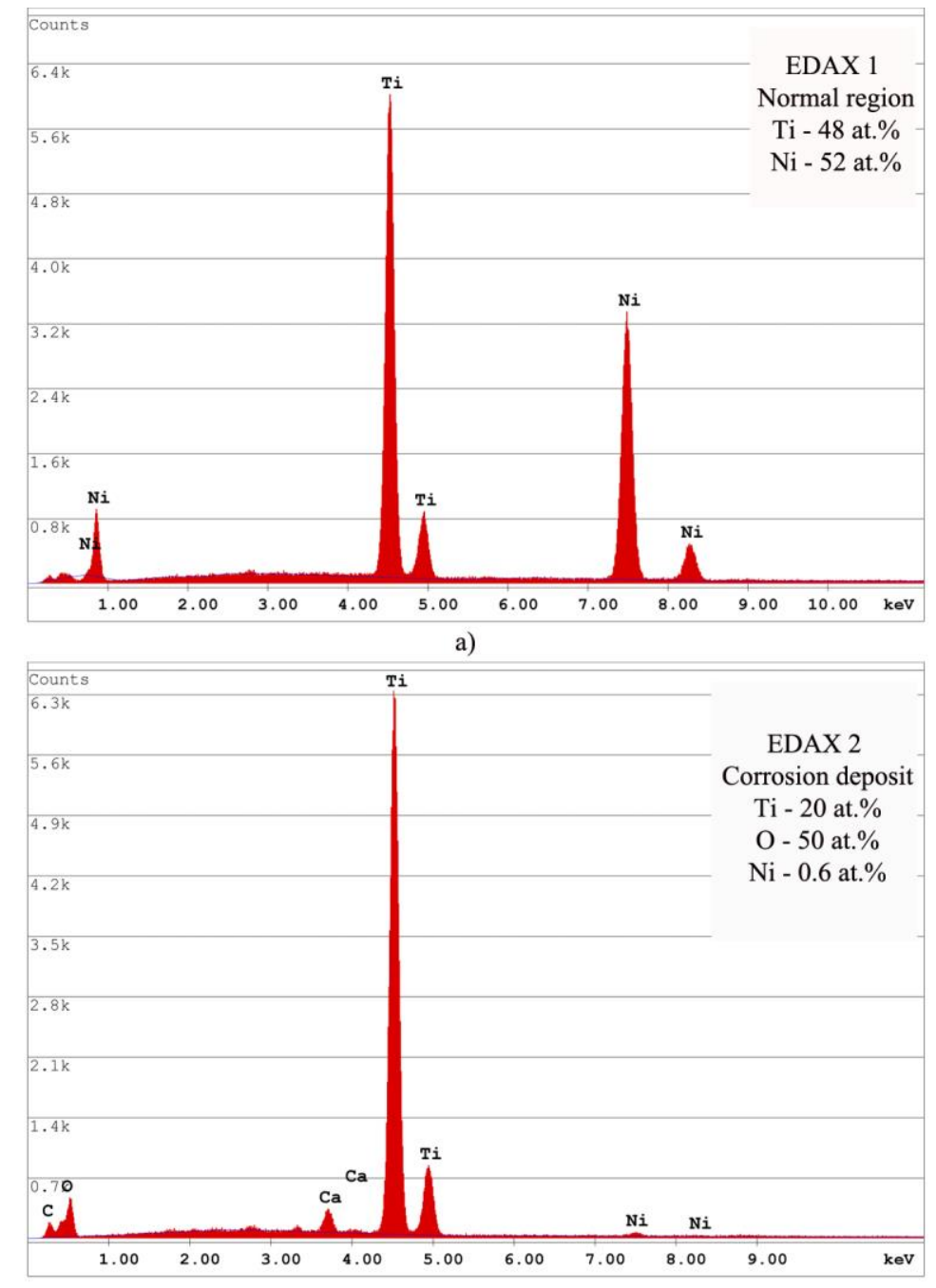

b)

Figure 5. EDAX analysis of explanted Nitinol rod: one of typical locations on the undamaged Nitinol rod (a) and on the corrosion deposit (b). Normal titanium to nickel distribution in the area without corrosion damage is observed. Significant decrease of nickel peak and presence of oxygen peak in the area with corrosion deposits are detected. Semi quantitative analysis revealed it to be titanium oxide

Fortunately, this patient was in the control group in a separate prospective study aiming to study the content of $\mathrm{Ni}$ in the blood of patients after implantation of spine devices with Nitinol rods. For this reason the data on $\mathrm{Ni}$ level in this patient blood before the primary surgery was available. Also, Ni ion level was measured 12 months later, before the revision operation. Comparison of pre and post-operative Ni ion levels in this patient showed no difference $(4.5 \pm 1$ and $4.2 \pm 0.8 \mathrm{ppb}$ respectively). The content of $\mathrm{Ni}$ ions in the tissues collected around the rod/pedicle screw junction was $0.5 \pm 0.1 \mu \mathrm{g} / \mathrm{g}$ which was within the range of the control group who did not have any implants, $0.1-1 \mu \mathrm{g} / \mathrm{g}(\mathrm{n}=8)$. 


\subsection{Baseline characterization of the rods}

The temperature of shape recovery of Nitinol rods used in the in-vitro tests was $20 \pm 2^{0} \mathrm{C}$. For this reason at the temperature of the tests (room temperature) rods were in austenitic (B2) state. Volume fraction of $\mathrm{Ti}_{4} \mathrm{Ni}_{2} \mathrm{O}_{x}$ particles in Nitinol rods was $1.4 \pm 0.2 \%$, average size $1.5 \pm 0.5$ microns, and their maximal size 5 microns (Figure 6a), which should provide good corrosion resistance to the rods [18].

Standard potentiodynamic tests were carried out on 3 rods up to $1000 \mathrm{mV}$. None of the samples reached breakdown potential $\left(\mathrm{E}_{\mathrm{b}}\right)$ and pitting was not observed on the surface indicating good corrosion resistance of the electropolished Nitinol rods (Figure $6 \mathrm{~b}$ ).

None of Ti6Al4V and CoCr rods reached breakdown potential $\left(\mathrm{E}_{\mathrm{b}}\right)$ and pitting was not observed on their surface. Open-circuit potential was $80 \pm 20 \mathrm{mV}$ for Ti6Al4V rods and $-154 \pm 23 \mathrm{mV}$ for CoCr rods.

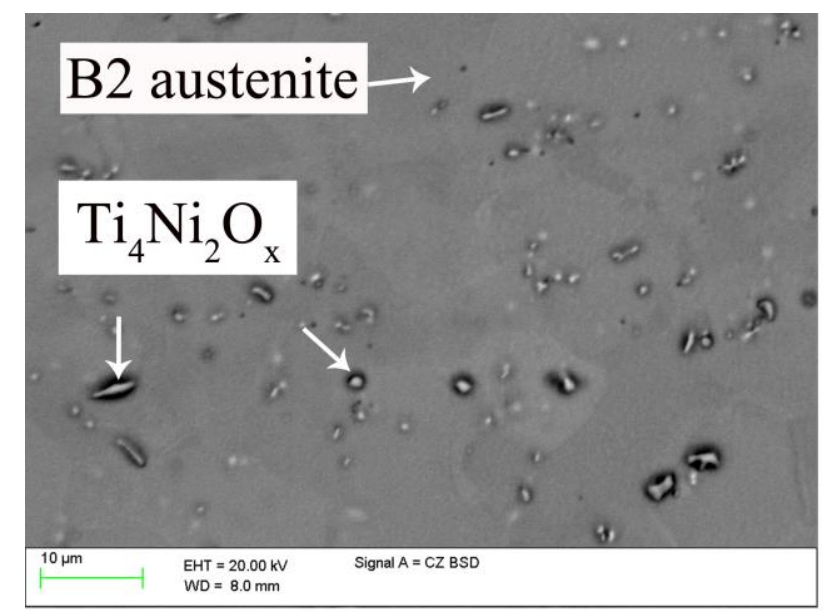

a)

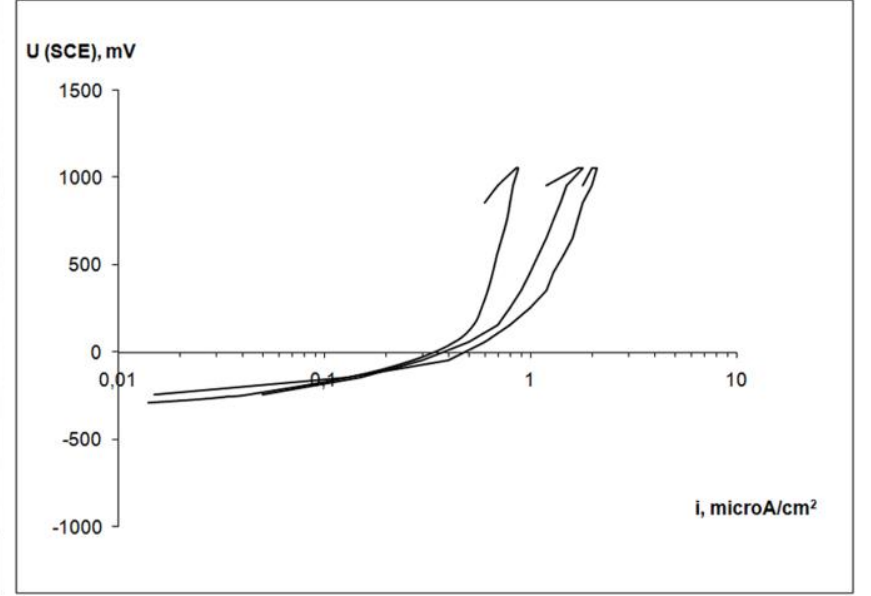

b)

Figure 6. Characterization of Nitinol rods used in the in-vitro fretting corrosion tests: (a) SEM image of microstructure; (b) Polarization curves

\subsection{In-vitro fretting corrosion tests}

\subsubsection{Short-term tests}

\section{Fretting corrosion current measurements}

Figure 7 represents peak-to-peak values of the fretting corrosion current developed by Nitinol rods locked in SS and TL titanium pedicle screws during short-term tests. Performance of Nitinol rods was compared to commercial titanium (Ti6Al4V) and $\mathrm{CoCr}$ rods.

Nitinol rods locked in SS pedicle screws showed significantly higher $(\mathrm{p}<0.05)$ values of fretting current compared to that of titanium or CoCr rods locked in either SS or TL screws. Mean and maximal 
values of the current developed by Nitinol rods were several folds higher than that of titanium and $\mathrm{CoCr}$ (Figure 7).

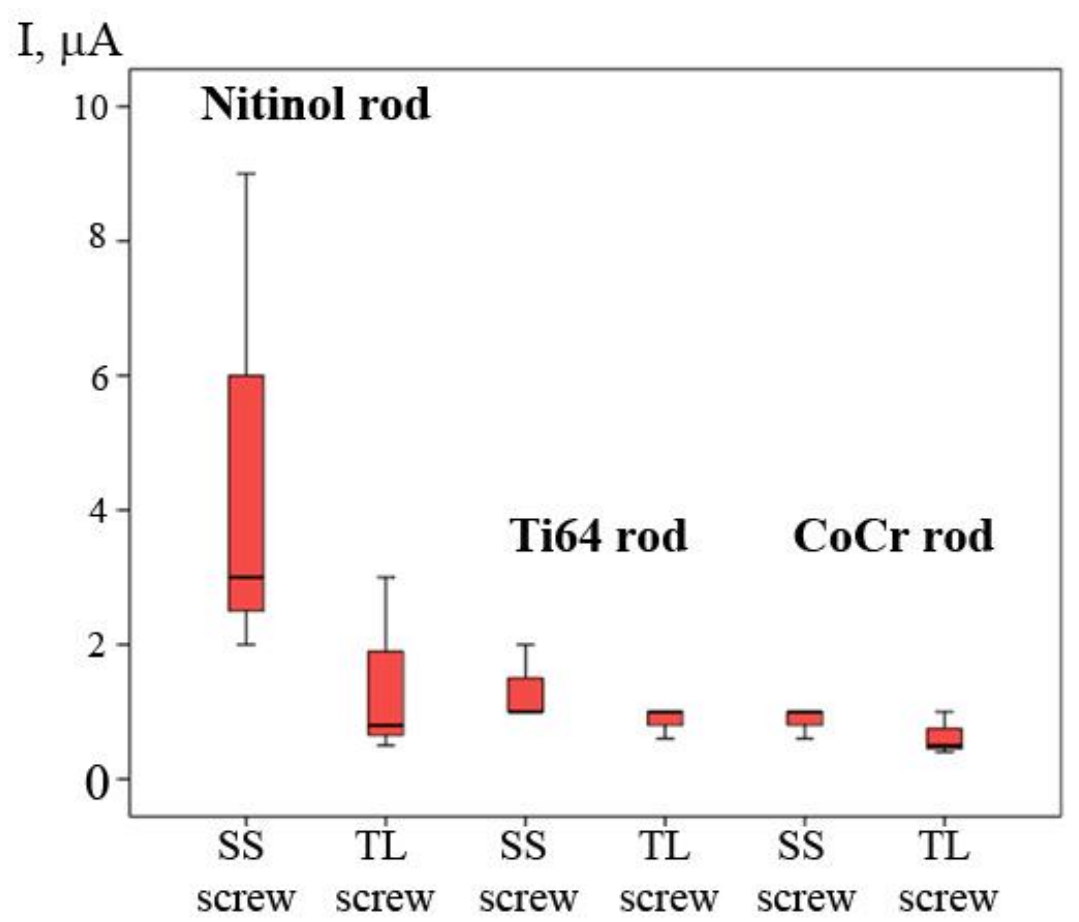

Figure 7. Peak-to-peak values of fretting corrosion current for Nitinol, Ti6Al4V and CoCr spinal rods locked in the SS and TL titanium pedicle screws after short-term tests

Better results were observed in case of measurement of fretting corrosion current for Nitinol rods locked in TL screws. The mean value of fretting corrosion current of Nitinol rods in TL screws was $1 \mu \mathrm{A}$ compared with $2.8 \mu \mathrm{A}$ measured in combination with SS screws. Nitinol rods locked in TL screws showed no statistically significant difference in the mean values of fretting corrosion current when compared with titanium or CoCr rods ( $\mathrm{p}=0.83$ and 0.37 respectively). However, maximal values of the fretting current for Nitinol rods were still higher compared with that of titanium or $\mathrm{CoCr}$, which implies less resistance of Nitinol to fretting corrosion even in TL pedicle screws. This suggestion was further confirmed by SEM and EDAX analysis of tested rods, which demonstrated corroded areas on the surface of Nitinol.

\section{SEM and EDAX analysis of corrosion patterns}

SEM and EDAX analysis of the surface of Nitinol rods locked in SS and TL titanium pedicle screws during short-term fretting corrosion tests revealed corrosion damage located under the edge of the screw head (Figure $8 \mathrm{a}, \mathrm{c}$ ). Corrosion damage included eroded areas with adjacent titanium oxide build-up (Figure $8 \mathrm{~b}$, d) similar to those observed on the Nitinol rod explanted from the patient (Figure 4). This implies accurate simulation and modeling of the in-vivo performance of rods in our in-vitro fretting corrosion tests. 
It was noted that the corroded area of Nitinol rods which were locked in TL screws was significantly smaller compared to Nitinol rods locked in SS type of pedicle screws (Figure 8 a and c), which qualitatively correlates with smaller values of fretting corrosion currents when TL screws were used.

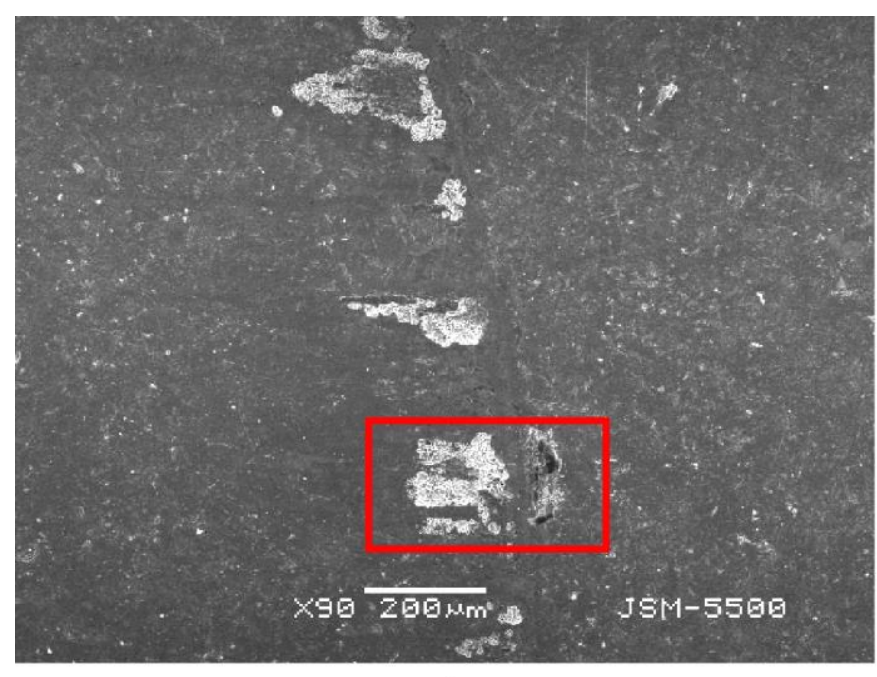

a)

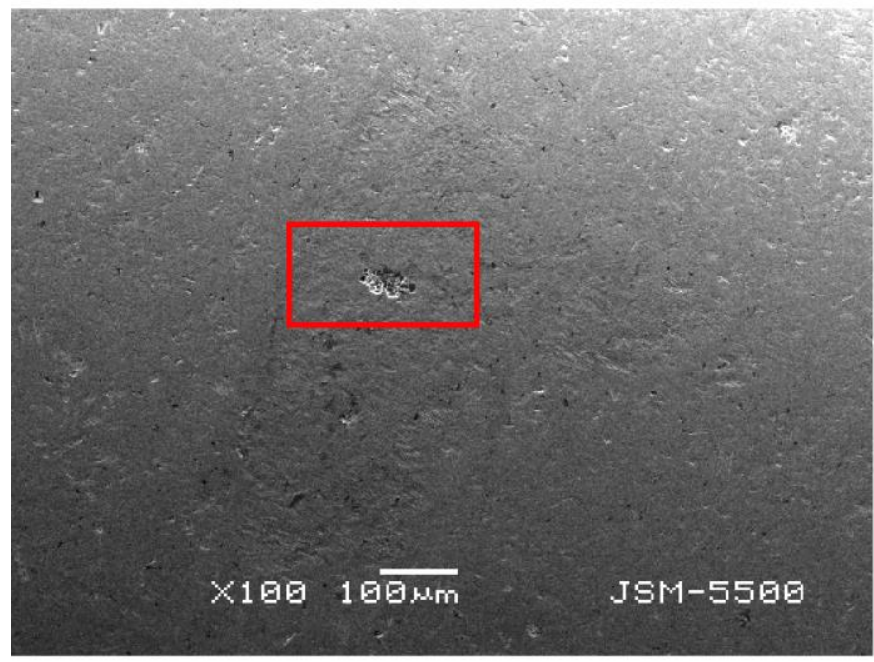

c)

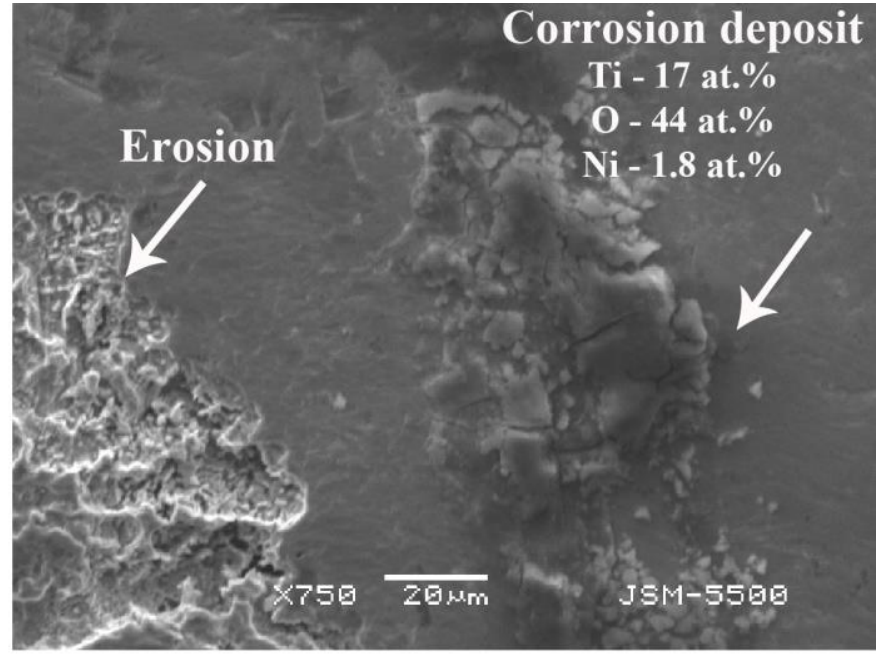

b)

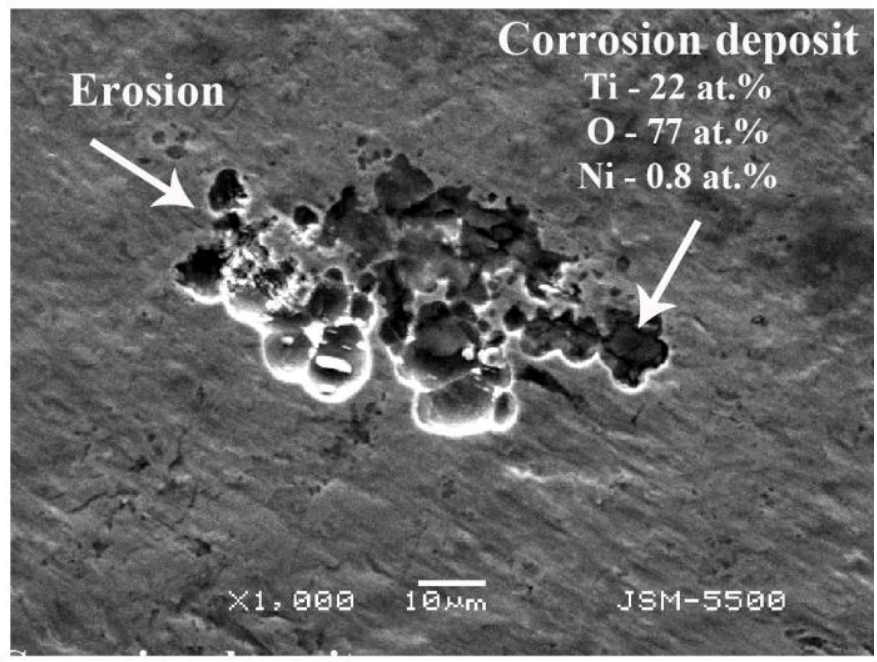

d)

Figure 8. SEM image and EDAX results of the surface of Nitinol rods locked in titanium pedicle screws of SS type ( $a$ and $b$ ) and in TL screws (c and d) after short-term fretting corrosion tests. All corrosion damage was observed under titanium screw head

On the other hand, analysis of commercial titanium and CoCr rods after in-vitro fretting corrosion tests reveals typical sand-blasted surface appearance (Figure 9). Mild indentation traces could be seen on these rods in the areas where they had been locked into pedicle screws, however, no corrosion or changing of surface chemical composition in these areas was established. 


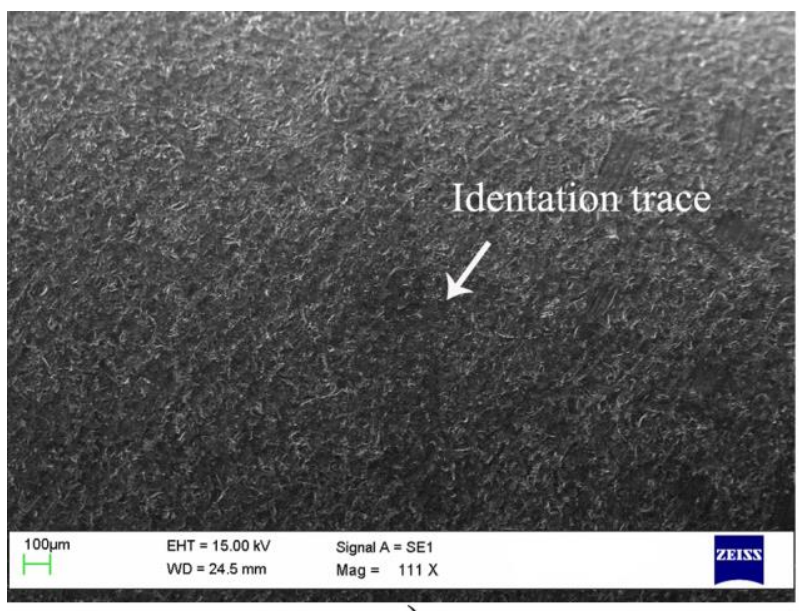

a)

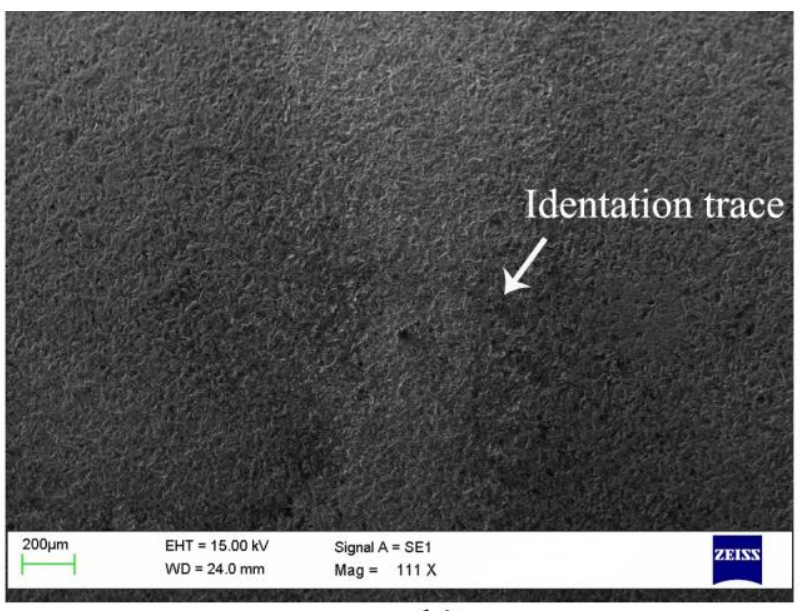

b)

Figure 9. SEM image of the surface of commercial sand-blasted Ti6Al4V (a) and CoCr (b) rods locked in titanium pedicle screws of SS type after short-term fretting corrosion tests.

\subsubsection{Long-term tests}

During long-term tests Nitinol rods were loaded for 2 million cycles with maximal load $350 \mathrm{~N}$ (bending moment $6.6 \mathrm{Nm}$ ). A higher load was not applied because of potential fatigue failure of the rods. During the final cycles of the test the maximal load was increased up to $650 \mathrm{~N}$ and peak-to-peak values of fretting corrosion current were monitored and compared to that after short-term tests.

It was hypothesized that the damage of Nitinol rods surface after long-term cyclic loading, which imposes more fretting damage, would result in higher values of fretting current and more pronounced corrosion damage. However, peak-to-peak values of fretting current after short-term and long-term were similar (Figure 10) with no statistically significant difference either for SS or for TL screws ( $\mathrm{p}=0.83$ for SS screws and $\mathrm{p}=1.0$ for $\mathrm{TL}$ screws respectively). The corrosion damage after long-term tests was not more severe compared to that observed after short-term tests. These results may imply that higher loads may be required to induce severer corrosion damage on Nitinol rods. 


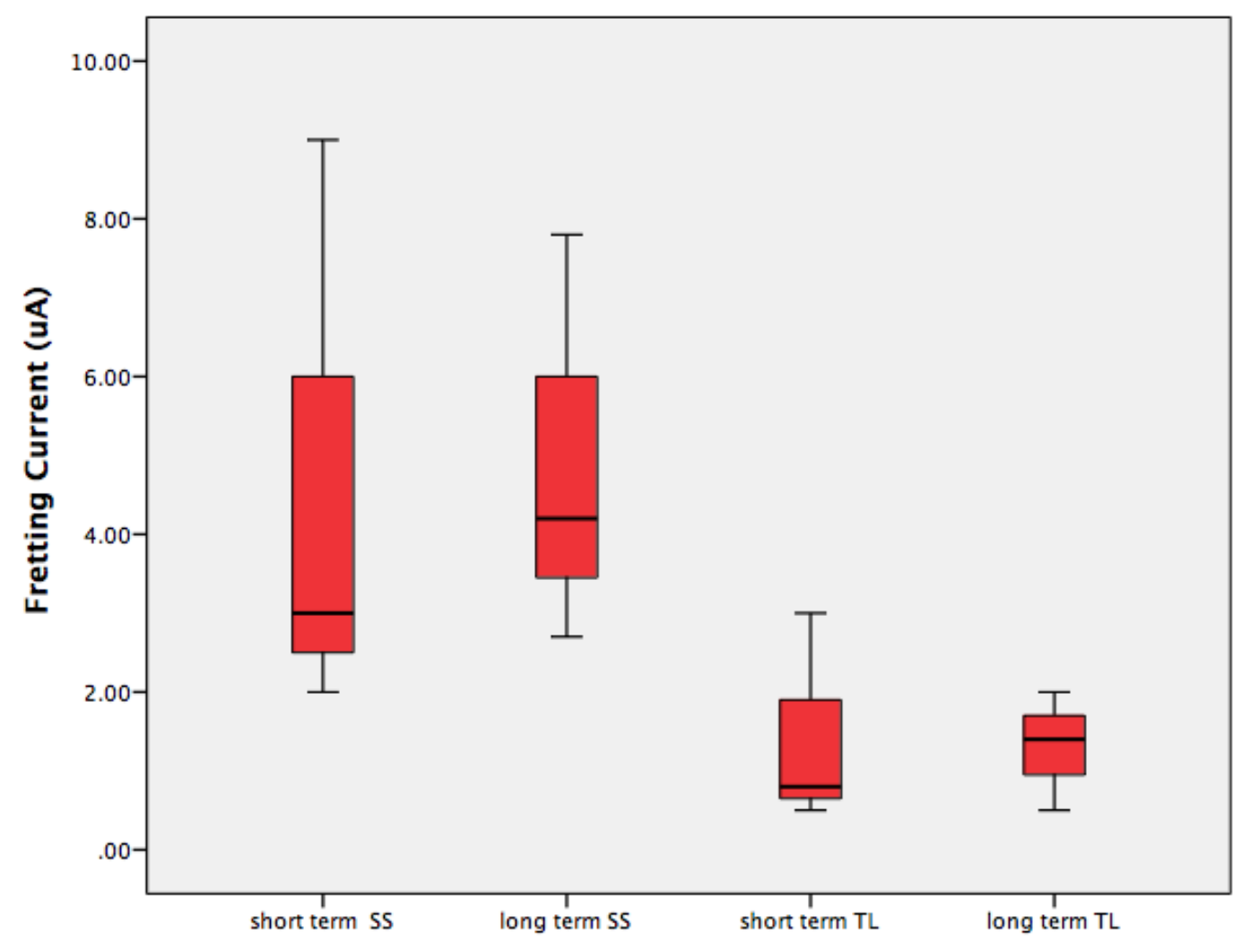

Figure 10. Peak-to-peak values of fretting corrosion current for Nitinol spinal rods locked in the SS and TL titanium pedicle screws after long-term tests

\section{Content of metal ions in the testing media}

The concentration of $\mathrm{Ni}, \mathrm{Ti}, \mathrm{Al}$ and $\mathrm{V}$ metal ions $(\mathrm{Ni}$ and $\mathrm{Ti}$ are constituents of Nitinol rods, while $\mathrm{Ti}, \mathrm{Al}$ and $\mathrm{V}$ are those of used pedicle screws) in the testing media was measured after long-term tests of Nitinol rods with SS screws using ICP-MS (Figure 11). These values were compared with the controls. Control values of these metal ions were measured in the same media that was used for fretting corrosion testing. Since leaching of metal ions is possible without any loading, assemblies including Nitinol rod locked in titanium SS pedicle screws were placed in the same amount of the control media for the same time period as was necessary to conduct long-term fretting corrosion tests (185 hours).

The mean values of $\mathrm{Ni}$ ion content in the media after fretting corrosion tests was 3 times higher compared with its content in the control solution. On the other hand, there was no statistically significant difference in the content of $\mathrm{Ti}, \mathrm{Al}$ and $\mathrm{V}$ between the control and test solutions ( $\mathrm{p}=0.6 ; 0.5$ and 0.2 for $\mathrm{Ti}, \mathrm{Al}$ and $\mathrm{V}$, respectively) (Figure 11). 


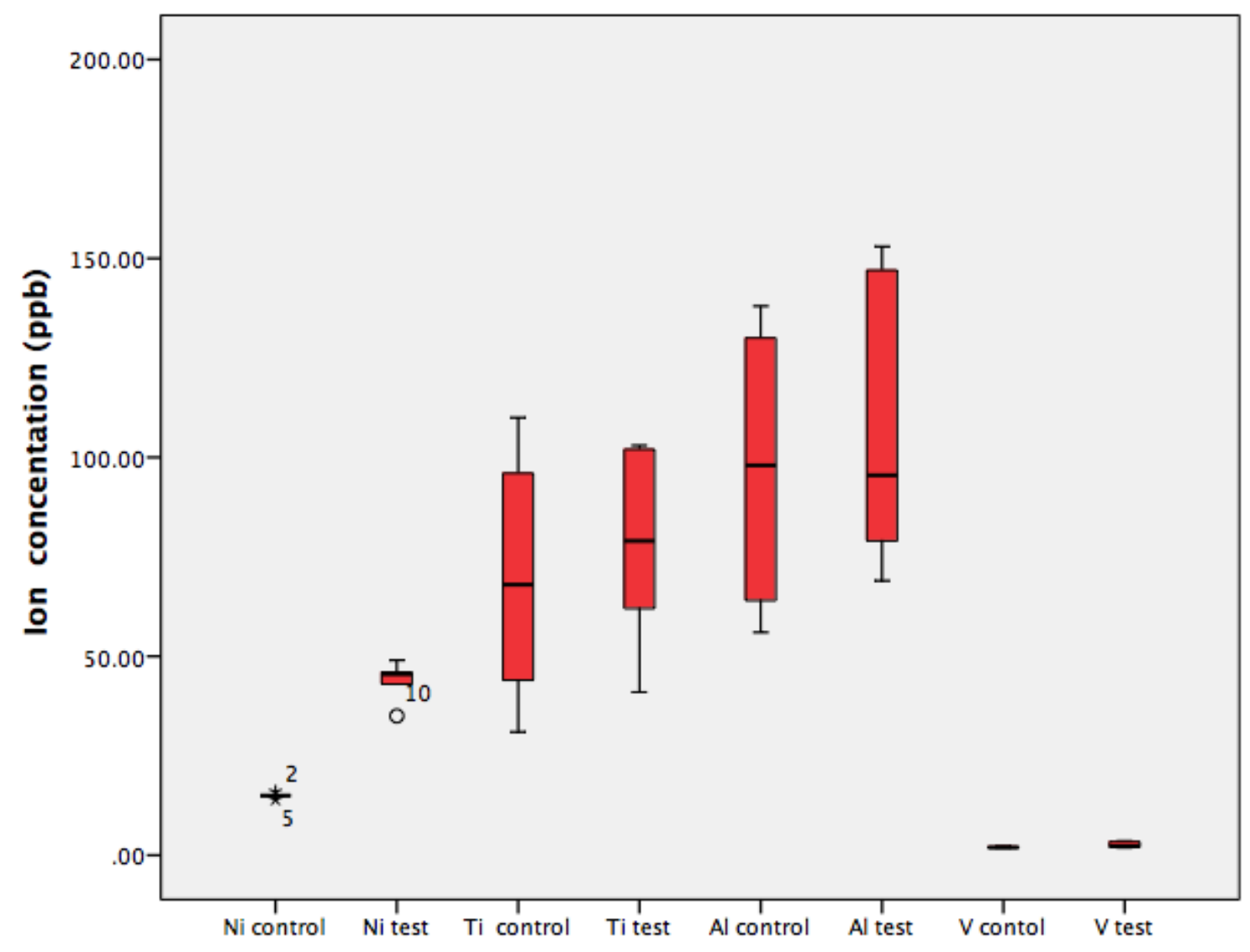

Figure 11. Content of $\mathrm{Ni}, \mathrm{Ti}, \mathrm{Al}$ and $\mathrm{V}$ metal ions in the testing media after long-term tests of Nitinol rods locked in titanium SS pedicle screws

\section{Discussion}

Corrosion patterns revealed on the surface of two Nitinol rods explanted from one patient 12 months after implantation were described and showed that corrosion was located in the areas where the rods were in contact with titanium pedicle screws (Figure 4a). It was noted that while some of these patterns were extensive and clearly visible to the unaided eye, others were smaller and required SEM imaging to visualize them. SEM and EDAX analysis showed that the corrosion damage was associated with erosion of the surface and with adjacent build-up of titanium oxide (Figure 4b-e). This type of damage is not normally observed on Nitinol. Usually just pitting [20-24] and very rarely erosions without build-up of titanium oxide [24] is seen on this material surface after electrochemical corrosion tests in physiological solutions and on explanted stents and orthodontic wires. As a result of corrosion, Ni ions could leach into the body from the rod and therefore, these were measured in the blood of the patient before explantation and in the tissues surrounding the Nitinol rod/Ti6Al4V pedicle screw junction during the revision surgery. However, it was found that the content of $\mathrm{Ni}$ in the blood was not higher when compared with values measured for this patient before the primary surgery. The content of $\mathrm{Ni}$ in the tissues was also not higher compared with the control group of patients who have not had any metal implants. 
In-vitro fretting corrosion tests of Nitinol rods carried out even for a short period of time (3600 cycles, 1 hour) led to the development of corrosion patterns very similar to the ones observed on the explanted rods in terms of their location, morphology and chemical composition (Figure 4 and 8), highlighting that Nitinol may be susceptible to this type of damage.

Elemental analysis of $\mathrm{Ni}, \mathrm{Ti}, \mathrm{Al}$ and $\mathrm{V}$ ions $(\mathrm{Ni}$ and $\mathrm{Ti}$ are constituents of Nitinol rods, while $\mathrm{Ti}, \mathrm{Al}$ and $\mathrm{V}$ are those of pedicle screws) in the fretting corrosion test media revealed that, after the tests, there was a 3 fold increase in the amount of $\mathrm{Ni}$, whereas the levels of $\mathrm{Ti}, \mathrm{Al}$ and $\mathrm{V}$ remained unchanged. It may be suggested that titanium ions emerging as a result of fretting corrosion are engaged in the formation of titanium oxide corrosion by-product and hence their content in the PBS solution is underestimated. On the other hand, $\mathrm{Ni}$ ions are released into the test solution. Taking into account the toxicity of nickel and increased sensivity of some patients to this element, its leaching as a result of fretting corrosion could be a potential concern [25-26], in spite of the previously reported high wear resistance of Nitinol under bovine serum lubrication [27].

Fatigue failure of Nitinol enhanced by the corrosion is another possible significant problem. For this reason, the main factors which cause this corrosion should be analyzed so that the development of this corrosion could be prevented.

It was hypothesized that much greater corrosion damage of Nitinol rods would occur when locked into SS compared with locking in TL pedicle screws. It was revealed that peak-to-peak values of fretting corrosion current were higher and there were more extensive corrosion patterns when Nitinol rods were tested in SS pedicles screws (Figure 7). We attribute this to the reduced contact area between the rod and the screw in the SS screw design and hence the higher mobility of the rods and presence of localized high stresses points that would lead to more extensive fretting damage of Nitinol rods.

Comparison of the results of our short-term fretting corrosion tests carried out for 3600 cycles (1 hour of testing) with that of a long-term test carried out for 2 million cycles (185 hours of testing) with a lower load revealed that neither the values of fretting current nor the extent of the corrosion damage were higher after long-term experiments, which indicates that higher loads may be the cause of the corrosion.

The performance of Nitinol rods was compared with that of commercially used titanium alloy (Ti6Al4V) and CoCr rods. It was found that fretting corrosion current measured for Nitinol rods locked in SS screws was significantly higher compared with that for Ti6A14V and CoCr rods. Also, no erosion or build-up of corrosion by-products was seen on the surface of Ti6Al4V and CoCr rods, indicating their superior behavior in our short-term in-vitro fretting corrosion test compared with Nitinol rods. However, another study of retrieved Nitinol, Ti64 and CoCr rods will be needed to compare the performance of rods made of these materials after long-term implantation in-vivo. 
On the other hand, there was no statistically significant difference between the mean values of the fretting current observed for Nitinol and titanium or CoCr rods locked in TL screws, thus highlighting the effect of a design with good load distribution and restriction of micro-movement. However, since minor corrosion damage was still found on Nitinol rods after tests in TL screws, the application of screws with stiffer lock might not be a complete solution for the prevention of Nitinol rod corrosion.

Another possible factor that could stimulate the observed corrosion damage might be the galvanic processes between Nitinol rods and Ti6A14V pedicle screws developed during fretting. Galvanic interaction of Nitinol with titanium alloys is known to be very small when the protective surface layers on these materials are intact [12-13]. However, this process is activated when such layers are damaged during fretting. The intensive build-up of titanium oxide $\mathrm{TiO}_{2}$ as a corrosion product is reported by Reigrut et al., who studied the corrosion behavior of scratched Nitinol rods locked into titanium pedicle screws under longterm immersion into a $0,9 \% \mathrm{NaCl}$ solution [16]. Since fretting behavior of Nitinol in corrosion media has so far been investigated only in a few studies, it was not possible to get sufficient evidence from the literature indicating that the build-up of titanium oxide as a corrosion product is observed when Nitinol is tested against other materials in a fretting environment. Trepanier et al. investigated corrosion performance of two Nitinol stents which were rubbed against one another in phosphate buffer saline (PBS) for 10 million cycles and then measured corrosion using potentiodynamic testing according to ASTM F2129. Increased susceptibility of the rubbed areas to pitting corrosion was seen. However, the build-up of titanium oxide as a corrosion product was not observed [28]. Unfortunately, in the other studies, wear tracks were not properly investigated [29-30]. Additional work will be needed in order to establish the effect of galvanic counteraction of Nitinol with other materials during fretting when the protective layer on its surface is damaged.

The presence of crevices in the rod/pedicle screw junction could also provide a negative input into the development of corrosion. In the few studies exploring this process with Nitinol, it was revealed that this material is more susceptible to pitting formation in crevices; however, the build-up of titanium oxide as a corrosion byproduct was not observed [28, 31-32].

\section{Conclusions}

The results of the in-vitro tests combined with retrievals analysis demonstrate that Nitinol spinal rods locked in titanium pedicle screws have inferior resistance to fretting corrosion compared with traditionally used Ti6Al4V and CoCr rods. Untypical corrosion damage including erosions combined with the build-up of titanium oxide as a corrosion product was observed on the surface of Nitinol rods in the areas where they were in contact with titanium pedicle screw head. The content of $\mathrm{Ni}$ in the blood of the patient, who had the rods with such damage explanted, was not higher when compared with values measured for this patient before the primary surgery. The content of $\mathrm{Ni}$ in the tissues was also not higher compared with the control group of patients who have not had any metal implants. However, the use of Nitinol rods in conjunction with titanium pedicle screws without further protection is not recommended because of the possible nickel 
leaching as a result of the corrosion process and of the increased risk of premature fatigue failure of the rods. Enhancing the locking mechanism of the pedicle screws designs may reduce mobility and damage of Nitinol rods. Another possible solution would be to use protective coatings, which would deter corrosion and prevent fretting. These solutions need to be explored as the advantages of using Nitinol rods include their super-elasticity which would be beneficial to patients by reducing adjacent spinal segment pathology.

\section{Acknowledgements:}

Funding: The work was financially supported by RFBR (Project number №15-03-05307)

\section{References}

1. Machado, L. G., \& Savi, M. A. (2003). Medical applications of shape memory alloys. Brazilian Journal of Medical and Biological Research, Vol. 36 No. 6, pp. 683-691.

2. Duerig, T. W., Pelton, A., \&Stöckel, D. (1999). An overview of nitinol medical applications. Materials Science and Engineering: A, Vol. 273, pp. 149-160.

3. Shabalovskaya, S., Anderegg, J. \&Humbeeck, J. (2008) Critical overview of Nitinol surfaces and their modifications for medical applications. Acta Biomaterialia, Vol. 4, pp. 447 - 467.

4. Schroeder, V. (2009). Evolution of the passive film on mechanically damaged nitinol. Journal of Biomedical Materials Research Part A, Vol 90 No. 1, pp. 1-17.

5. Es-Souni, M., Es-Souni, M., \& Fischer-Brandies, H. (2005) Assessing the biocompatibility of NiTi shape memory alloys used for medical applications. Analytical and bioanalytical chemistry. Vol. 381 No.3, pp.557-567.

6. Ryhänen, J., Kallioinen, M., Serlo, S., Peramaki, P., Junila, J., Sandvik, P., Niemelä, E. \& Tuukkanen, J. (1999) Bone healing and mineralization, implant corrosion and trace metals after nickel-titanium shape memory metal intramedullary fixation. J. Biomed. Mater. Res. Vol. 47, pp. $472-480$.

7. Wever, D. J., Veldhuizen, A. G., De Vries, J., Busscher, H. J., Uges, D. R. A., \& Van Horn, J. R. (1998) Electrochemical and surface characterization of a nickel-titanium alloy. Biomaterials. Vol. 19 No. 7-9, pp.761-769.

8. Trepanier, C., Leung, T. K., Tabrizian, M., Yahia, L. H., Bienvenu, J. G., Tanguay, J. F., \&Bilodeau, L. (1999). Preliminary investigation of the effects of surface treatments on biological response to shape memory NiTi stents. Journal of biomedical materials research, Vol. 48 No. 2, pp.165-171.

9. Yoshihara, H. (2013). Rods in spinal surgery: a review of the literature. The Spine Journal. Vol. 13 No.10, pp.1350-1358. 
10. Kim, Y., Zhang, H., Moon, B., Park, K., Ji, K., Lee, W., Oh, K., Ryu, G. \& Kim, H. (2007) Nitinol spring rod dynamic stabilization system and Nitinol memory loops in surgical treatment for lumbar disc disorders: short-term follow up. Neurosurg Focus, Vol. 22 No. 1, pp. 1-9.

11. Cheung, K., Kuong, E., Samartzis, D. \&Yeung, K. (2011). Assessing the Safety and Efficacy of a Novel Superelastic Rod in Comparison to Conventional Titanium Rod for Scoliosis Curve Correction. $18^{\text {th }}$ International Meeting on advanced spinal techniques. July 13-16, 2011. Copenhagen: SRS.

12. Venugolapan R. \&Trepanier C. (2000) Assessing the corrosion behaviour of Nitinol for minimally invasive device design. Minimally Invasive Therapy \& Allied Technologies, Vol. 9, pp. 67-75.

13. Kassab, E. J., \& Gomes, J. P. (2013). Assessment of nickel titanium and beta titanium corrosion resistance behavior in fluoride and chloride environments. The Angle Orthodontist, Vol. 83 No. 5, pp. 864-869.

14. Kok, D., Firkins, P. J., Wapstra, F. H., \&Veldhuizen, A. G. (2013). A new lumbar posterior fixation system, the memory metal spinal system: an in-vitro mechanical evaluation. BMC musculoskeletal disorders, Vol. 14 No. 1, pp.1.

15. Lukina E. In-vitro and in-vivo investigation of Nitinol corrosion behavior for pedicle screw constructs //The International Conference on Shape Memory and Superelastic Technologies (SMST),(May 18-22, 2015). - ASM, 2015 - p.94-95.

16. Reigrut ,J. et.al. "The tribo-corrosion of nitinol in pedicle screws .Tribo-corrosion: research, testing, and applications", ASTM Publications, STP1563 (2013), pp.105-124.

17. Rondelli, G. (1996). Corrosion resistance tests on NiTi shape memory alloy. Biomaterials, Vol. 17 No. 20, pp.2003-2008.

18. Wohlschlögel, M., Steegmüller, R., \&Schüßler, A. (2014). Effect of Inclusion Size and Distribution on the Corrosion Behavior of Medical-Device Grade Nitinol Tubing. Journal of Materials Engineering and Performance, Vol. 23 No.7, pp.2635-2640.

19. Rohlmann A, Graichen F , Bergmann G . (2002) Loads on an internal spinal fixation device during physical therapy. J Bone Joint Surg Am 2002 ; Vol. 82 pp. 44 - 52.

20. Eliades, T., Eliades, G., Athanasiou, A. E., \& Bradley, T. G. (2000). Surface characterization of retrieved NiTi orthodontic archwires. The European Journal of Orthodontics, Vol. 22 No. 3, pp. 317326.

21. Guidoin, R., Marois, Y., Douville, Y., King, M. W., Castonguay, M., Traoré, A., ...\& Becquemin, J. P. (2000). First-generation aortic endografts: analysis of explanted Stentor devices from the EUROSTAR Registry. Journal of Endovascular Therapy, Vol. 7 No. 2, pp. 105-122. 
22. Halwani, D. O., Anderson, P. G., Brott, B. C., Anayiotos, A. S., \& Lemons, J. E. (2010). Clinical device-related article surface characterization of explanted endovascular stents: Evidence of in vivo corrosion. Journal of Biomedical Materials Research Part B: Applied Biomaterials, Vol. 95 No. 1, pp. 225-238.

23. Lin, J., Guidoin, R., Wang, L., Zhang, Z., Paynter, R., How, T., ...\& Dionne, G. (2013). Long-term resistance to fracture and/or corrosion of the nitinol wires of the Talent stent-graft: observations from a series of explanted devices. Journal of long-term effects of medical implants, Vol. 23 No.1 pp.4559.

24. Heintz, C., Riepe, G., Birken, L., Kaiser, E., Chakfé, N., Morlock, M., ...\& Imig, H. (2001). Corroded nitinol wires in explanted aortic endografts: an important mechanism of failure?. Journal of Endovascular Therapy, Vol. 8 No. 3, pp. 248-253.

25. Lacy, S. A., Merritt, K., Brown, S. A., \& Puryear, A. (1996). Distribution of nickel and cobalt following dermal and systemic administration with in vitro and in vivo studies. Journal of biomedical materials research. Vol. 32 No. 2, pp.279-283.

26. Hayes, R. B. (1997). The carcinogenicity of metals in humans. Cancer Causes \& Control, Vol. 8 No. 3, pp. 371-385.

27. Lukina, E., Kollerov, M., Meswania, J., Wertheim, D., Mason, P., Wagstaff, P., ...\& Blunn, G. (2015). Analysis of retrieved growth guidance sliding LSZ-4D devices for early onset scoliosis and investigation of the use of Nitinol rods for this system. Spine, Vol. 40 No. 1, pp. 17-24.

28. Trépanier, C., Gong, X. Y., Ditter, T., Pelton, A., Neely, Y., \& Grishaber, R. (2008). Effect of wear and crevice on the corrosion resistance of overlapped stents. In SMST-2006. Proceedings of the International Conference on Shape Memory and Superelastic Technologies. Menlo Park, CA: SMST Society (pp. 265-275).

29. Yangtao, X., Yan, Y., \&Tiandong, X. (2008). Study on Fretting Friction Coefficient between NiTi Shape Memory Alloy and Human Bone in Hank's Solution. Rare Metal Materials and Engineering, Vol. 37 No. 7, pp. 1201-1205.

30. Kosec, T., Močnik, P., \&Legat, A. (2014). The tribocorrosion behavior of NiTi alloy. Applied Surface Science, Vol. 288, pp. 727-735.

31. Cheng, F. T., Lo, K. H., \& Man, H. C. (2007). An electrochemical study of the crevice corrosion resistance of NiTi in Hanks' solution. Journal of Alloys and Compounds, Vol. 437 No.1, pp. 322328.

32. Pound, B. G. (2006). Susceptibility of nitinol to localized corrosion. Journal of Biomedical Materials Research Part A, Vol. 77 No. 1, pp. 185-191. 